\title{
TUMBUKAN TAK-ELASTIK PARTIKEL SEBAGAI MODEL TERBENTUKNYA ASTEROID
}

\author{
Sparisoma Viridi ${ }^{1, \mathrm{a})}$, Budi Dermawan ${ }^{2, \mathrm{~b})}$ \\ ${ }^{1}$ Prodi Fisika, FMIPA, Institut Teknologi Bandung, Jalan Ganesha 10, Bandung 40132 \\ ${ }_{2}^{2}$ Prodi Astronomi, FMIPA, Institut Teknologi Bandung, Jalan Ganesha 10, Bandung 40132 \\ Email: ${ }^{a)}$ dudung@ fi.itb.ac.id, ${ }^{\text {b) }}$ budider@as.itb.ac.id
}

\begin{abstract}
Abstrak
Suatu asteroid diduga merupakan kumpulan partikel yang bertumbukan tak-elastik sehingga membentuk suatu agregat. Ikatan yang terjadi antar partikel diasumsikan hanyalah disebabkan gaya gravitasi. Gaya normal diperkenalkan untuk mencegah dua partikel berada pada posisi yang sama akibat gaya gravitasi. Parameter kontaktopi diperkenalkan dan teramati bahwa nilainya bertambah dengan semakin padatnya susunan agregat dan pada akhirnya akan mencapai nilai saturasi. Dalam sistem yang disimulasikan dengan jumlah partikel $N=22$ diperoleh bahwa kontaktopi mencapai nilai saturasi pada $C=35$.
\end{abstract}

Kata-kata kunci: partikel granular, dinamika molekuler, asteroid, kompaksi.

\begin{abstract}
An asteroid is assumed to be constucted from particles inealastic collision, which later forms an agregate of particles. Binding between particles is caused only by gravitational force. Normal force is introduced to prevent two particles collapsing into single point as they are colliding and attracted to to each other due to gravitational force. Contactotpy as parameter is presented and it is observed that its value increasing as the agregate becoming denser, and at the end it achieves saturation value. In the simulated system with number of particles $N=22$ it is obtained that the contactopy reaches saturation value $C=35$.
\end{abstract}

Keywords: granular particles, molecular dynamics, asteroid, compaction.

\section{PENDAHULUAN}

Asteroid merupakan suatu obyek yang menarik apabila dilihat dari bidang material granular, terlebih setelah tersedianya foto-foto resolusi tinggi mengenai permukaan asteroid Itokawa yang diperoleh dalam misi Hayabusa [1]. Terdapatnya bongkahan batuan berukuran lebih besar di atas lapisan batuan yang berukuran lebih kecil dikaitkan dengan fenomena efek kacang Brasil (EKB) [2]. Simulasi mengenai material granular dalam sistem planet kemudian dilakukan dengan menggunakan pendekatan bola keras (hard sphere) [3], maupun bola lunak (soft sphere) [4] pada tumbukan antara dua buah partikel baik berbentuk bola ataupun lingkaran. Dilaporkan pula terdapatnya segregasi pada sistem dengan gravitasi sendiri (self-gravitating) suatu agregat material butiran [5], yang agak mirip dengan EKB. Eksperimen dan simulasi fenomena EKB umumnya menempatkan partikel granular dalam wadah dan semua partikel mengalami gaya gravitasi yang tegak lurus dengan permukaan alas 
dalam wadah. Hal ini kurang sesuai dengan keadaan di asteroid yang terlalu kecil dibandingkan dengan permukaan bumi yang dapat dianggap datar dibandingkan dengan wadah material granular. Untuk itu suatu alas dalam wadah dengan gravitasi sendiri diusulkan dalam tulisan ini, yang diduga terbentuk dari batuan-batuan yang berinteraksi dengan gaya gravitasi dan gaya normal (untuk saat ini gaya gesek diabaikan).

\section{SIMULASI}

Terdapat dua interaksi antar partikel, yaitu atraktif dan repulsif. Interaksi atraktif menjangkau rentang yang jauh (long range), sementara interaksi repulsif yang sebatas ukuran partikel (short range). Interaksi pertama tak-lain adalah gaya gravitasi, di mana gaya gravitasi yang bekerja pada partikel $i$ akibat adanya partikel $j$ adalah

$$
\vec{G}_{i j}=-G \frac{m_{i} m_{j}}{r_{i j}^{2}} \hat{r}_{i j}
$$

dengan

$$
\begin{gathered}
\vec{r}_{i j}=\vec{r}_{i}-\vec{r}_{j}, \\
r_{i j}=\left|\vec{r}_{i j}\right|=\sqrt{\vec{r}_{i j} \cdot \vec{r}_{i j}}, \\
\hat{r}_{i j}=\frac{\vec{r}_{i j}}{r_{i j}},
\end{gathered}
$$

dan $G$ adalah konstanta universtal gravitasi. Lalu, interaksi kedua adalah gaya normal yang menggambil model pegas linier (linear spring-dashpot) [6]

dengan

$$
\vec{N}_{i j}=\left[k_{N} \xi_{i j}-\gamma_{N} \operatorname{sign}\left(\xi_{i j}\right) \frac{d \xi_{i j}}{d t}\right] \hat{r}_{i j},
$$

$$
\begin{gathered}
\xi_{i j}=\max \left(0, R_{i}+R_{j}-r_{i j}\right), \\
\frac{d \xi_{i j}}{d t}=-v_{i j}, \\
\operatorname{sign}(x)= \begin{cases}-1, & x<0, \\
0, & x=0, \\
1, & x>0,\end{cases}
\end{gathered}
$$

dan $R_{i}, R_{j}$ adalah jari-jari partikel $i, j$, berturut-turut.

Dengan menggunakan hukum kedua Newton tentang gerak, percepatan partikel $i$ pada saat $t$ akibat berinteraksi dengan $N-1$ partikel lainnya dalam sistem dapat diperoleh melalui

$$
\vec{a}_{i}=\frac{1}{m_{i}} \sum_{\substack{j \neq i, j=1}}^{N}\left(\vec{G}_{i j}+\vec{N}_{i j}\right) .
$$

Massa partikel $m_{i}$ diperoleh dari

$$
m_{i}=\frac{4}{3} \pi R_{i}^{3} \rho_{i}
$$

Selanjutnya, metode integrasi numerik Euler akan dapat memberikan kecepatan dan posisi baru dari partikel pada waktu $t+\Delta t$, yaitu

$$
\begin{gathered}
\vec{v}_{i}(t+\Delta t)=\vec{v}_{i}(t)+\vec{a}_{i} \Delta t \\
\vec{r}_{i}(t+\Delta t)=\vec{r}_{i}(t)+\vec{v}_{i}(t) \Delta t .
\end{gathered}
$$

Dalam implementasinya, pengulangan Persamaan (5), (6.a), dan (6.b) yang akan mengubah posisi partikel-partikel - dikenal sebagai metode dinamika molekuler (molecular dynamics, MD), perlu diselipkan suatu langkah untuk membuat kecepatan partikel-partikel menjadi nol sehingga proses perhitungan menjadi lebih cepat. Suatu periode $T$ digunakan sehingga akan terpenuhi bahwa

$$
\vec{v}_{i}(n T)=0, n=0,1,2, . .
$$


Bagaimana perngaruh dari nilai $T$ ini akan diamati dalam simulasi.

Selanjutnya susunan partikel perlu dikarakterisasi melalui parameter kontaktopi $C$ yang dapat diperoleh dari energi potensial kontak $U_{C}$ [7], yang dimodifikasi menjadi

$$
C=\sum_{i=1}^{N} \sum_{j>1}^{N} \operatorname{sign}\left(\xi_{i j}\right) \text {. }
$$

Telah diamati bahwa pada fenomena EKB nilai $C$ akan semakin besar dan mencapai maksimum saat fenomena ini terhenti [8].

\section{HASIL DAN PEMBAHASAN}

Nilai Parameter-parameter yang digunakan dalam simulasi MD ini diberikan dalam Tabel 1, apabila tidak diberikan keterangan lainnya. Akibat adanya gaya gravitasi $\vec{G}_{i j}$ maka susunan partikel akan menjadi semakin padat, yang dapat ditunjukkan dengan bertambahnya nilai kontaktopi $C$ seperti dalam Gambar 1. Untuk susunan dengan $N=22$ ini nilai saturasi $C$ tercapai dengan nilai 35, yang mungkin dapat sedikit agar berbeda apabila dilakukan variasi posisi awal partikel-partikel.

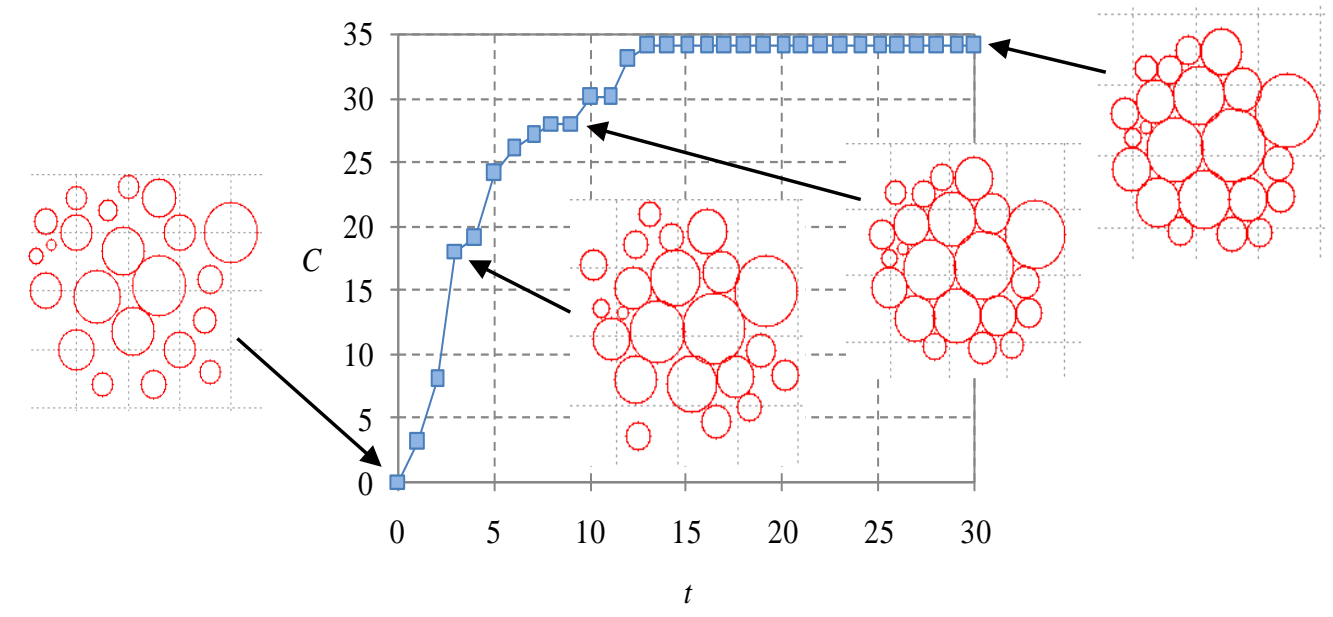

Gambar 1. Kontaktopi $\mathrm{C}$ sebagai fungsi waktu t dan beberapa ilustrasi susunan partikelnya untuk t = 0, 3, 9, dan 30 .

Tabel 1. Nilai parameter-parameter standar dalam simulasi.

\begin{tabular}{ccc}
\hline No. & Parameter & Value \\
\hline 1. & $k_{N}$ & $10^{4}$ \\
2. & $\gamma_{N}$ & $5 \times 10^{-1}$ \\
3. & $T$ & $10^{2}$ \\
4. & $G$ & $10^{-7}$ \\
5. & $\Delta t$ & $10^{-2}$ \\
6. & $N$ & 2 \\
7. & $R_{i}$ & $1-2.5$ \\
8. & $\rho_{i}$ & 2000 \\
\hline
\end{tabular}

Dengan menggunakan syarat awal yang sama dilakukan variasi nilai-nilai dari $k_{N}, \gamma_{N}$, dan $T$. Hasil akhir pada $t=30$ untuk masing-masing variasi diberikan dalam Gambar 2, 3, dan 4. 


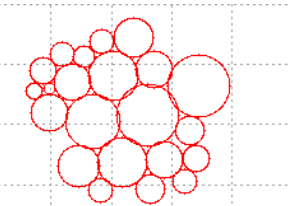

(a)

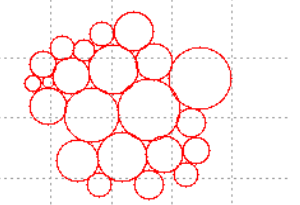

(c)

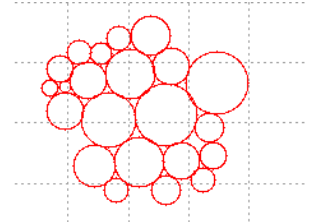

(e)

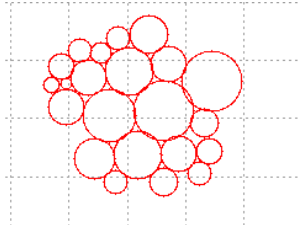

(b)

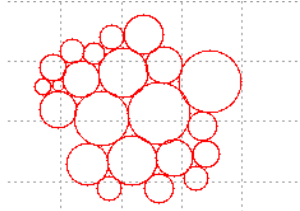

(d)

Gambar 2. Susunan akhir agregat untuk berbagai nilai $\mathrm{k}_{\mathrm{N}}$ : (a) $10^{3}$, (b) $2 \times 10^{3}$, (c) $6 \times 10^{3}$, (d) $10^{4}$, dan (e) $2 \times 10^{4}$.

Variasi nilai $k_{N}$ tidak memberikan susunan akhir partikel yang terlalu berbeda sebagaimana pula variasi nilai $\gamma_{N}$ sebagaimana ditunjukkan dalam Gambar 2 dan 3. Hal ini dapat dipahami karena $k_{N}$ hanya akan mengubah seberapa besar irisan antar dua butiran dan $\gamma_{N}$ menentukan energi yang hilang dalam setiap tumbukan antara dua partikel. Akan tetapi terdapat hal yang berbeda dengan variasi nilai $T$ yang memberikan hasil seperti diberikan dalam Gambar 4, di mana susunan akhir agregat partikel ditentukan oleh nilai $T$ ini.

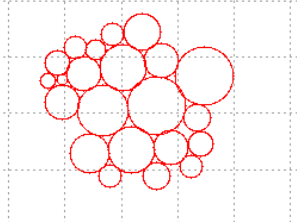

(a)

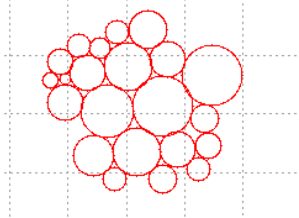

(c)

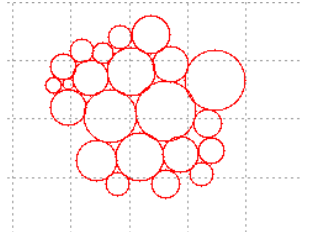

(e)

Gambar 3. Susunan akhir agregat untuk berbagai nilai $\gamma_{\mathrm{N}}$ : (a) 0.1 , (b) 0.2 , (c) 0.3 , (d) 0.4 , dan (e) 0.6 .

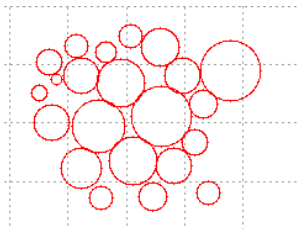

(a)

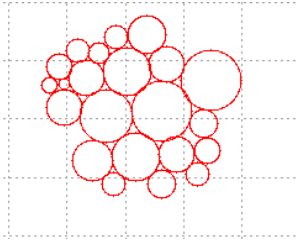

(d)

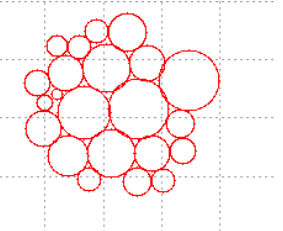

(c)

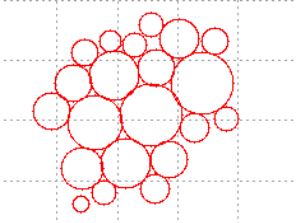

(e)

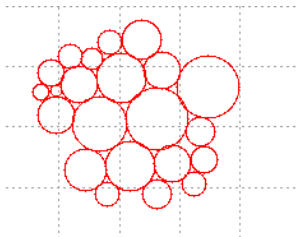

(b)

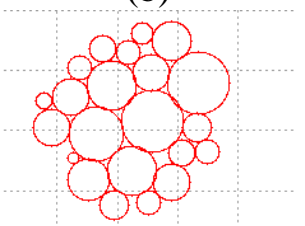

(d)

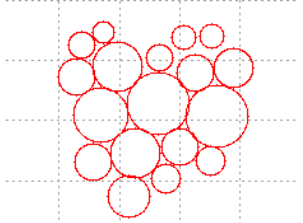

(f)
Gambar 4. Susunan akhir agregat untuk berbagai nilai T: (a) 1, (b) 10, (c) 100, (d) 200, (e) 300, dan (f) 500 . 
Nilai $T$ adalah suatu periode untuk memaksa kecepatan semua partikel menjadi nol seperti telah diungkapkan dalam Persamaan (8). Langkah ini bertujuan agar simulasi dapat berjalan lebih cepat ketimbang menunggu suku yang mengandung $\gamma_{N}$ dalam Persamaan (3) berpengaruh.

Bagaimana pengaruh dari $T$ terhadap $C$ susunan akhir partikel dapat dilihat dalam Gambar 5, di mana terlihat bahwa dengan semakin besarnya nilai $T$ akan semakin kecil nilai $C$. Evolusi kompaksi $C$ sebagai fungsi waktu $t$ dalam Gambar 1 dan bagaimana pengaruh dari parameter-parameter $k_{N}, \gamma_{N}$, dan $T$ tidak terlepas dari susunan awal partikel dan juga distribusi ukuran partikel, yang diberikan dalam Gambar 6. Terlihat bahwa partikel berukuran rata-rata $R=1$ memiliki jumlah paling banyak yang kemudian diikuti dengan berukuran rata-rata $\mathrm{R}=1.5$, sementara ukuran rata-rata lainnya berjumlah kurang dari $30 \%$.

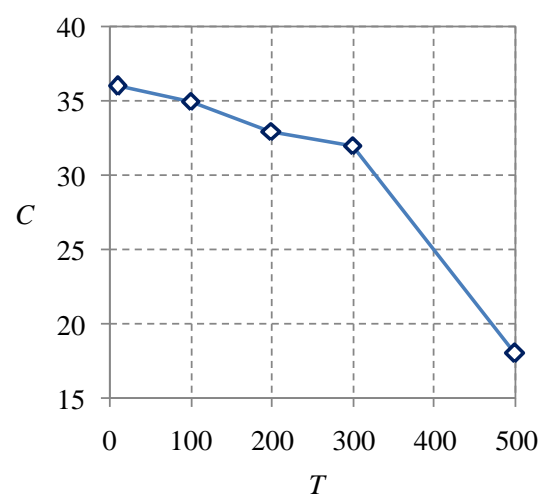

Gambar 5. Kontaktopi akhir C susuanan partikel sebagi fungsi $\mathrm{T}$.

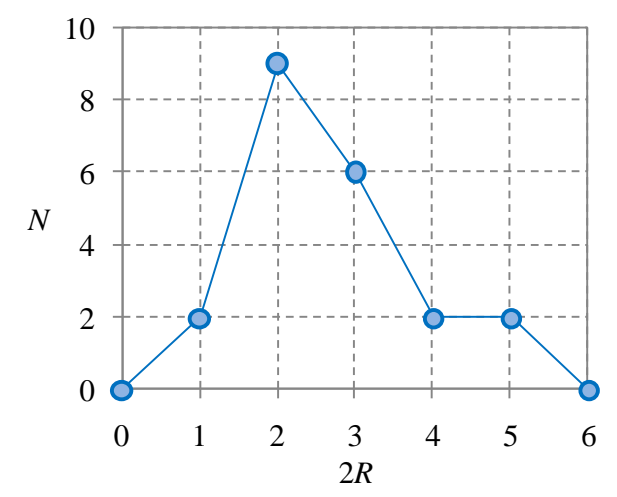

Gambar 6. Distribusi ukuran partikel $D=2 R$ yang digunakan dalam simulasi.

Untuk satu jenis ukuran partikel nilai kompaksi dapat diperkirakan dalam susunan dua-dimensi berbentuk HPC (hexagonal close packed) sebagaimana diilustrasikan dalam Gambar 7 berikut. Diberikan susunan-susunan akhir partikel yang dianggap stabil untuk $N=2,3, . .7$. Susunan-susunan lain seperti linier dan zig-zag tidak ditampilkan karena dianggap masih akan berubah menunju susunan-susunan seperti dalam gambar.

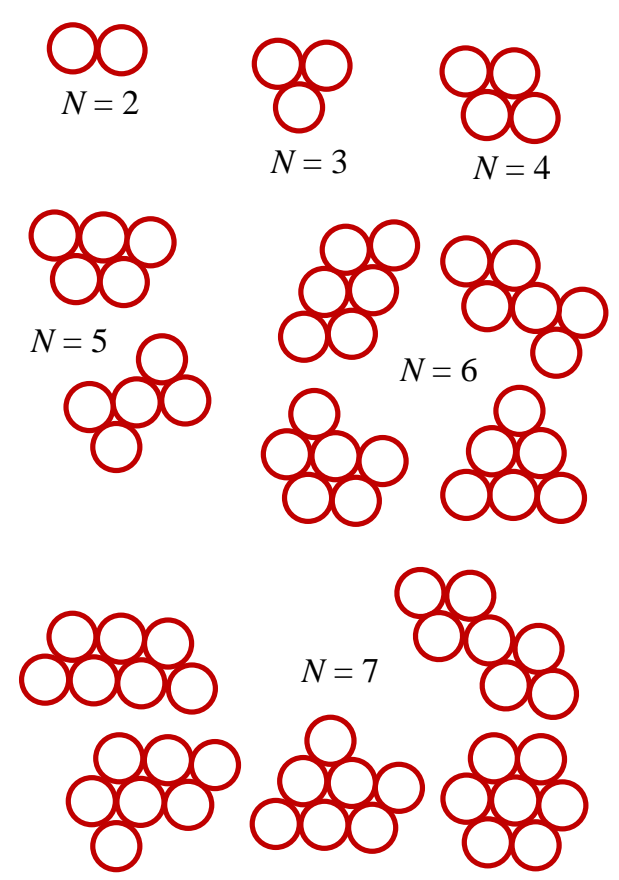

Gambar 7. Susunan HCP dalam dua-dimensi partikel berukuran sama dengan $N=1,2, . ., 7$. 
Kontaktopi untuk partikel berukuran sama dengan $N=1,2, . ., 7$ diberikan dalam Gambar 8 .

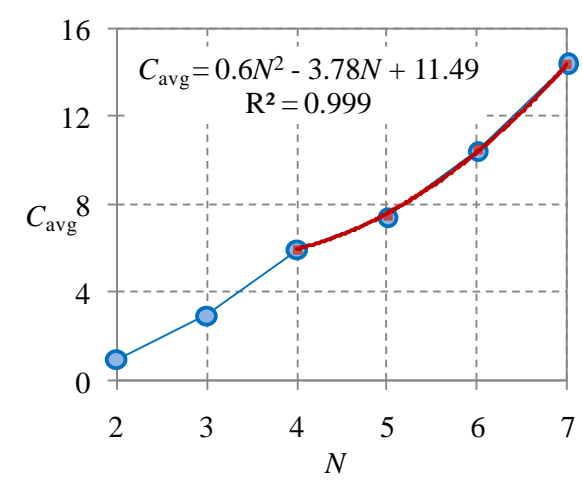

Gambar 8. Rata-rata kontaktopi $C_{\text {avg }}$ untuk berbagai jumlah partikel berukuran seragam N.

Suatu perumusan empirik dapat dibuat untuk mengaitkan antara nilai rata-rata kontaktopi $C_{\text {avg }}$ sistem HCP dua-dimensi yang stabil untuk partikel berukuran seragam (monodispersed) dengan jumlah partikel $N$ dalam bentuk

$$
C_{\text {avg,mono }}=0.6 N^{2}-3.78 N+11.49,
$$

yang berlaku untuk $N \geq 4$. Persamaan (10) ini dimulai saat susunan akhir partikel pertama kalinya memiliki degenerasi, yaitu mulai $N=4$. Setelah itu, dengan semakin besar $N$ semakin banyak susunan akhir stabil dari partikel yang dapat dibentuk, atau degenerasi akan semakin besar.

Dengan menggunakan Persamaan (10) dalam sistem dengan ukuran partikel beragam yang telah disimulasikan sebelumnya diperoleh $C_{\text {avg }}=217.73$ atau $C \approx 218$ untuk satu susunan akhir, yang dalam hal ini jauh lebih besar dari nilai $\mathrm{C}=35$ yang diperoleh. Untuk sementara dapat dituliskan bahwa Persamaan (10) akan memberikan nilai maksimum kontaktopi yang dapat dicapai oleh sistem dengan ukuran partikel beragam (polydispersed)

$$
C_{\text {poly }} \leq C_{\text {avg,mono }} \text {, }
$$

yang tentunya memerlukan pembuktian lebih lanjut, selain dari yang ditunjukkan beberapa kemungkin-annya dalam Gambar 9.

Susunan dalam Gambar 9 belum menunjukkan kemungkinan yang memenuhi Persamaan (11) karena titik $\mathrm{N}=4$ merupakan titik pertama dalam Persamaan (10). Diperlukan ilustrasi untuk susunan dengan $\mathrm{N} \geq 5$ untuk menjelaskannya. Untuk $\mathrm{N}=5$ dapat dibentuk berbagai susunan akhir partikel dan nilai kontaktopinya sebagaimana diberikan dalam Gambar 10. Susunan dengan nilai kontaktopi tertentu, misalnya $C=12$ hanya dapat diperoleh bila rasio ukuran partikel mengikuti aturan tertentu. Sekilas dengan melihat Gambar 10 susunan akhir yang tidak memenuhi Persamaan (11) diduga tidak terlalu banyak sehingga persamaan tersebut untuk sementara tetap berlaku. 

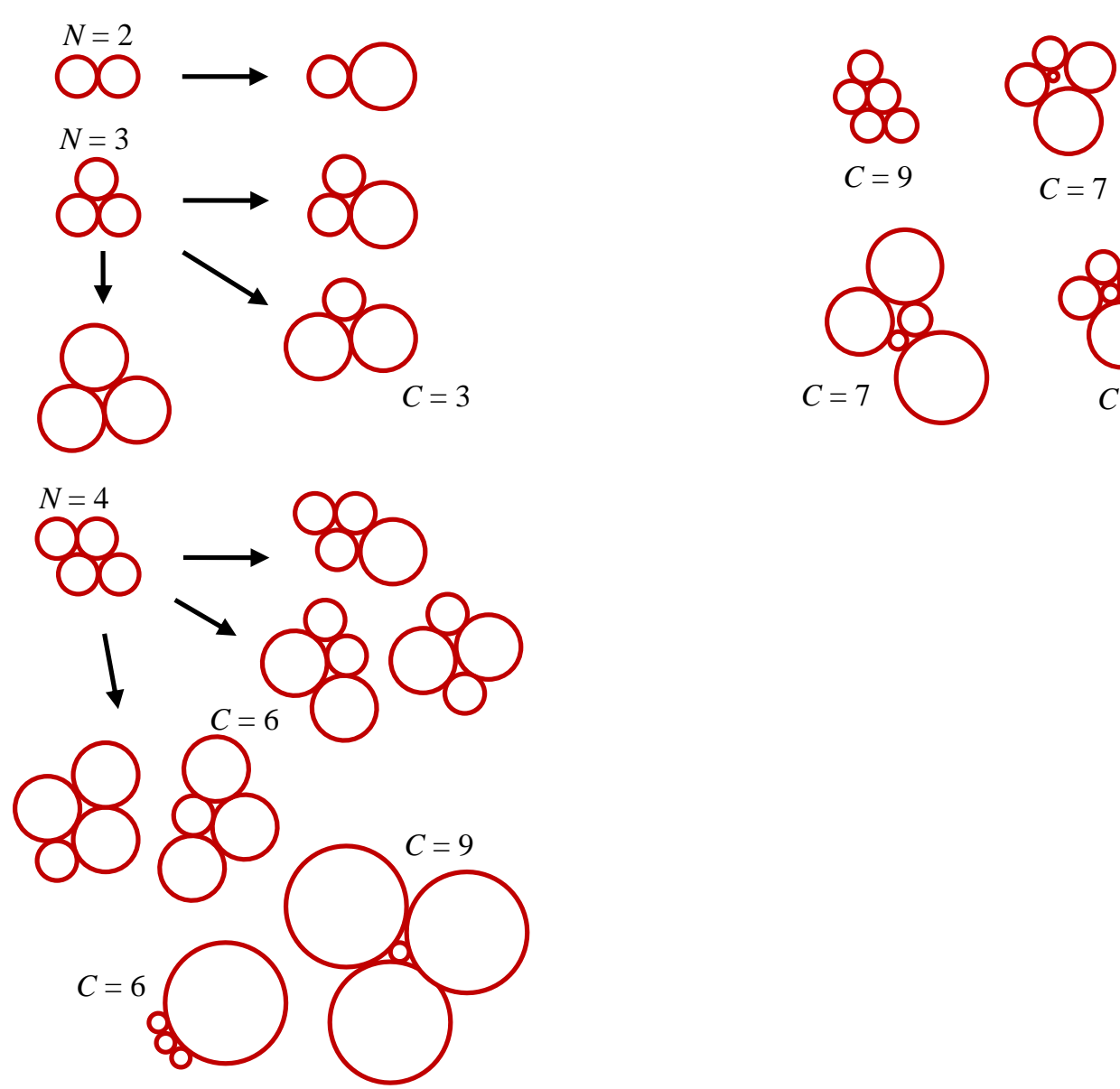

Gambar 9. Beberapa kemungkinan susunan akhir partikel dan nilai kompaktopinya untuk $\mathrm{N}=1,2,3,4$.

Gambar 10. Beberapa kemungkinan susunan akhir partikel dan nilai kompaktopinya untuk $\mathrm{N}=5$.

\section{SIMPULAN}

Telah dapat disimulasikan pembentukan awal asteroid dalam 2-d. Teramati bahwa kontaktopi $C$ bertambah dengan semakin kompaknya susunan partikel. Parameter $k_{N}$ dan $\gamma_{N}$ tidak terlalu berpengaruh ke susunan akhir partikel yang terbentuk. Waktu membuat $v=0$ dengan $T$ tertentu terlihat berpengaruh, di mana semakin besar $T$ akan membuat nilai $C$ semakin kecil. Dugaan batas atas nilai $C$ untuk sistem partikel berukuran beragam telah pula diusulkan dikaitkan dengan $C_{\text {avg }}$ sistem partikel berukuran seragam.

\section{UCAPAN TERIMAKASIH}

Terima kasih kepada Kemenristekdikti atas dukungan dalam penelitian ini pada tahun 2016 dengan skema Penelitian Unggulan Perguruan Tinggi (Nomor 583x/I1.C01/PL2016) dan Panitia SNF UNJ 2016 atas undangan-nya sebagai pembicara undangan pada sesi paralel dalam melakukan sosialisasi hasil penelitian ini.

\section{DAFTAR ACUAN}

[1] H. Miyamoto, H. Yano, D.J. Scheeres, S. Abe, O. Barnouin-Jha, A.F. Cheng, H. Demura, R.W. Gaskell, N. Hirata, M. Ishiguro, T. Michikami, A.M. Nakamura, R. Nakamura, J. Saito, S. Sasaki, Regolith migration and sorting on asteroid Itokawa, Science 316 (2007), p. 10111014. 
[2] G.V. Punyakoti, Brazil nuts help unlock the asteroid's boulder mystery, Current Science 107 (2014), p. 945-946.

[3] D.C. Richardson, K.J. Walsh, N. Murdoch, P. Michel, Numerical simulations of granular dynamics: I. Hard-sphere discrete element method and tests, Icarus 212 (2011), p. 427-437.

[4] S. Matsumura, D.C. Richardson, P. Mitchel, S.R. Schwartz, R.-L. Ballouz, The Brazil nut effect and its application to asteroids, MNRAS 443 (2014), p. 3368-3380.

[5] P. Sánchez, D.J. Scheeres, M.R. Swift, Impact driven size sorting in gelf-gravitating granular aggregates, 41st Lunar and Planetary Science Conference (2010), p. 2634.

[6] J. Schäfer, S. Dippel, D.E. Wolf, Force schemes in simulations of granular materials, J. Phys. I France 6 (1996), p. 5-20.

[7] S. Viridi, S.N. Khotimah, Widayani, Novitrian, Fluctuation theorem application on 2-d granular materials configurations, Advanced Materials Research 1123 (2015), p. 12-15.

[8] S. Viridi, S.N. Khotimah, Widayani, Novitrian, Competition between potential energy minimization and number of contact points in two-dimension granular materials exhibiting Brazil-nut effect, AIP Conf. Proc. 1677 (2015), p. 070001. 